Validation of an Arabic Version of the Spiritual Well-Being Scale

Ahmad S. Musa ${ }^{1}$

David J. Pevalin ${ }^{2}$

${ }^{1}$ Princess Salma Faculty of Nursing, Al al-Bayt University, Mafraq, Jordan

${ }^{2}$ School of Health and Human Sciences, University of Essex, Colchester, UK

Correspondence to:

Ahmad S. Musa, PhD, RN

Dean Assistant/ Princess Salma Faculty of Nursing

Al al-Bayt University, Mafraq, Jordan

P.O.Box (130040) - Postal code 25113

Email: Ahmad_cns1@yahoo.com 


\section{Validation of an Arabic Version of the Spiritual Well-Being Scale}

\section{Abstract}

This paper reports a validation study of an Arabic language version of the Spiritual Well-Being Scale (SWBS). The study was conducted two phases. Phase one was a pilot study at a major government university in Jordan ( $N=86$, students). Phase two was the main study conducted in five large regional hospitals in Jordan ( $N=63$, patients). The SWBS was translated from English to Arabic and reviewed by an expert panel for language, cultural and spiritual consistency. The Arabic version of the SWBS was revised after the results of the pilot study and further reviewed by an expert panel. The resulting data were subjected to descriptive and factor analysis. Results showed that the final version of the SWBS used in the main study had a two-factor structure consistent with previous studies. Descriptive data for a range of demographic variables are presented. Issues of inadequate translation and lack of variation in responses for some items are identified and the results discussed in light of dominant Islamic theological frameworks 


\section{Validation of an Arabic Version of the Spiritual Well-Being Scale}

\section{Introduction}

The Spiritual Well-Being Scale (SWBS) was originally designed over 20 years ago (Ellison, 1983; Paloutzian \& Ellison, 1982) and has become a widely used and well validated instrument (Ellison \& Smith, 1991).

Despite that the SWBS was developed primarily in a Christian context and influenced by the Judeo-Christian concept of well-being, Ellison (1983) argued that the SWBS is a nonsectarian instrument that can be utilized by other religions that experience God in personal terms. Therefore, the SWBS was designed to be widely used to measure spiritual well-being in religious and non-religious individuals and also for individuals from different religions and cultures. Consequently, the SWBS has been used in settings such as colleges, universities, hospitals, and clinics using samples such as students, housewives, nurses, elderly, hospitalized patients, evangelical believers, ethical/cultural Christians, and non-Christian.

Scale and sub-scale structure

During the development of the SWBS, Ellison (1983) found two main common factors using data obtained from 206 students studying at three religiously oriented colleges. These two factors were classified as religious well-being (RWB) and existential well-being (EWB). The two subscale structure was confirmed by Kirschling and Pittman (1989) using data from 70 caregivers for terminally ill hospice patients. Their results showed internal consistency of the main scale and both sub-scales along with a high correlation between the two subscales.

Other research has disputed the two-factor structure of the SWBS. Ledbetter, Smith, Fischer, Vosler-Hunter, and Chew (1991) pointed out that the factor analysis used by Ellison 
(1983) to evaluate the factor structure of SWBS was not appropriate and the results of their analysis were not clearly reported. They suggested that the high correlation between the two subscales found by Ellison (1983) and Kirschling and Pittman (1989) indicated that the SWBS may be re-conceptualization to a one-factor structure that describes a one dimension of wellbeing. The confirmatory factor analysis performed by Ledbetter, Smith, Fischer et al. (1991) failed to confirm either the hypothesised one-factor or two-factor solution previous research had found. They concluded that there were no one or two factors that shape the SWBS and the factor structure of the scale is not clear. They further suggested that the factorial complexity of the SWBS might be related to diversity of items that include different behaviors, beliefs, and feelings.

Two further studies have used samples of college students. Miller, Fleming and BrownAnderson (1998) evaluated the differences in factor structure of the SWBS between Caucasians and African-Americans. They found a three-factor structure in the Caucasian sample which closely matched the two factors identified in the earlier studies, but found a five-factor structure in the African-American sample. Genia (2001) used a religiously heterogeneous sample of college students in Washington, DC and found a two-factor structure to the SWBS.

A sample of psychiatric inpatients was used by Scott, Agresti, and Fitchett (1998) who found a three-factor structure to the SWBS and labeled the three factors: affiliation, alienation, and dissatisfaction with life.

Overall, it appears that most studies into the structure of the SWBS have been based on samples of college students with other studies based on caregivers and psychiatric inpatients. While most studies using a college student sample generally support the two-factor structure 
there are notable differences such as those found by Miller et al. (1998). Also see Slater, Hall and Edwards (2001) for a review of the usefulness of the SWBS and other measures of spirituality.

The purpose of this study was to translate the SWBS into Arabic and adapt it to a Muslim population and then to assess the validity of the translation by analyzing the internal structure of the SWBS utilizing data from a pilot study of Jordanian college students and a main study of Jordanian hospital patients post coronary artery bypass graft (CABG) surgery.

\section{Method}

Spiritual Well-Being Scale (SWBS)

The SWBS is 20 -item self-report paper-pencil instrument. It takes $10-15$ minutes to complete. Each item is answered on a 6-point Likert scale ranging from 'strongly agree' to 'strongly disagree'. The SWBS consists of two subscales, which are RWB and EWB subscales. Ten items are designed to measure RWB and contain the word "God" and 10 items measure EWB and ask such things as life satisfaction and direction. About half of the items are worded in a reversed direction to minimize any possible response bias. Each SWBS item is scored from 1 to 6, with a higher number representing greater well-being. Negatively worded items are reverse scored. Even numbered items assess existential well-being and odd numbered items assess religious well-being. The overall SWB score is computed by summing responses to all twenty items. The total scores of SWBS range from 20 to 120.

\section{Translation}

This study used asymmetrical translation by back-translation which emphasizes loyalty to the source (original) instrument and its concepts during the translation process (Jones, Lee, 
Philips, Zhang, \& Jaceldo, 2001). This process retains the meaning and the structure of the instrument and its items whilst making appropriate adaptations suitable for another culture. In this study, suitability included easily understandable and meaningful content for the Arabic participants. Asymmetrical translation can be achieved by using one of three options: one-way translation, translation by committee, and back-translation (Carlson, 2000). Back-translation is the most recommended and commonly used method in cross-cultural research (Jones, Lee, Philips et al., 2001; Jones \& Kay, 1992; Carlson, 2000; Hyrkäs, Appelqvist-Schmidlechner, \& Paunonen-IImonen, 2003).

The SWBS was translated into the Arabic language using the back-translation method. The original 20 items of the SWBS were first translated from the English language into the Arabic language by a bilingual expert. Then, another bilingual expert retranslated the items from Arabic back to English. After the back-translation, one of the authors (AM) compared the back-translated version with the original English version to examine the equivalence between the two. This equivalence included examining if the meaning of each item was maintained. AM discussed discrepancies with the back-translator and agreed minor changes that maintained the same meaning of items in both versions. Residual disagreement over the words "private prayer" in item 1 in the original version was left to the decision of the panel experts in the next phase.

In the next phase, the revised Arabic version and the original English version of the instrument were further validated by a working group of four bilingual experts. This panel of experts included two members with doctoral degree in nursing and two other members with doctoral degrees in Linguistics (one in Arabic and another in English). They assembled to ensure 
the content and semantic equivalence of the scale to suit the Arabic Islamic culture and to assess the language complexity that might influence readability such as clarity of wording and familiarity of the used words within the new culture. All members of panel were bilingual and had previous translation experience. Two members of the panel had intensive experience in research, management, instrument development, and practical issues in the nursing field. The other two had extensive experience of translation, research, and applied linguistics in both Arabic and English.

The evaluation of content and semantic equivalence was qualitative in nature and the panel of experts gave their feedback verbally to AM during the meeting. They used equivalent words and phrases that maintained the idiomatic meaning of the original SWBS items rather than merely translated items word by word. Most of the 20 items were easily translated into Arabic. However, two items created problems: "private prayer" (item 1) and "I believe that God is impersonal and not interested in my daily situations" (item 5). "Private prayer" lacked appropriate Arabic words and so it was translated into different words while maintaining semantic equivalence. The two parts of item 5, "I believe that God is impersonal" and "not interested in my daily situations", are opposite in meaning to each other and had to be translated differently in positive terms instead of negative terms as listed in the original instrument to suit the Islamic culture. The words "personally" in items 7 and 13 and "personal" in item 9 were omitted during translation because they lacked appropriate Arabic words for Muslims. Additionally, "satisfaction", "well-being", and "fulfilled" each of which are presented in two items in the SWBS also lacked an appropriate Arabic word and had to be translated according to the context of the item. 


\section{Factor analysis}

To examine factor structure of the SWBS, an exploratory factor analysis was conducted using Principal Component analysis with a Direct Oblimin rotation from SPSS. Kaiser's criterion and a scree test were used to assess the number of factors. The suitability of data for performing factor analysis was assessed using the Kaiser-Meyer-Olkin (KMO) measure of sampling adequacy and Bartlett's Test of Sphericity.

\section{Results}

Pilot study

After the initial translation process, the Arabic version of the SWBS was pilot tested for reliability, validity, and score distribution on a convenience sample of nursing students. This study was conducted in summer 2004 at a major government university in Jordan with second year undergraduate nursing students. A total of 87 undergraduate nursing students undertook to complete the Arabic version of SWBS. The instrument was distributed to the subjects during class time. The compliance of students was voluntary. Feedback about the clarity and ease of completion of the Arabic version was also received from the subjects. Completion time ranged from 5 to 7 minutes similar to completion time for the original version of SWBS. There were 75 complete responses which were used for the factor analysis. The 11 responses with missing values on one or two items were included in the descriptive statistics after factor determination by using mean item replacement. The one response with three missing items was dropped from the analysis.

Initial inspection of the correlation matrix revealed adequate correlations between the items. The data met the standards of the KMO measure of sampling adequacy $(>0.60)$ and the 
Bartlett's Test of Sphericity $(p<0.05)$. The Principal Components analysis revealed the presence of seven factors with Eigenvalues greater than 1 which accounted for a cumulative total of $64 \%$ of the overall variance. By using Kaiser's criterion alone, seven factors would be identified. However, for Kaiser's criterion to be accurate, the number of variables must be less than 30 and the mean of commonalties after extraction exceeds 0.7 or the sample size must be greater than 250 and the mean of commonalties after extraction exceeds 0.6 (Field, 2004). The mean of the commonalties for the data was $\mathbf{0 . 6 4}$, but the sample size was only 75 . Therefore, Kaiser's criterion may not be accurate. By examining the scree test there was a clear break between the third and fourth factors indicating that only the first three factors should be retained. The first three factors still explained a relatively large amount of variance. It was decided to extract only three factors. The three factors were rotated using Direct Oblimin rotation as the factors were expected to be correlated. A comparison between orthogonal and oblique rotations revealed no significant difference in factor structure.

Table 1 presents the structure matrix which of the factor loadings for each item onto each factor. The majority of items loaded substantially onto only one factor. The exceptions were items 5,18 , and 20 whose strongest loading is shown.

$<$ Table 1 about here >

The majority of items in factor 1 relate to a person's belief that God takes care of persons and one's experience of a positive relationship with God; therefore this factor was labeled "Affiliation". The majority of items in factor 2 relate to one's sense of dissatisfaction with life and to one's sense of distance from God; therefore, this factor was labeled "Alienation". The items in factor 3 relate to one's sense of satisfaction with life; therefore, this 
factor was labeled "Satisfaction with Life". This factor included all the items of positive existential aspects designed by Paloutzian and Ellison (1982) to measure the positive existential well-being. However, overall these findings are more consistent with the findings of Scott et al. (1998) that showed a three factor solution for SWBS.

Table 2 presents the mean, standard deviation, range, and Cronbach's alpha of the SWBS and the three subscales. SWBS and the subscales were examined for normality using histograms and the Shapiro-Wilk test. The SWBS and Alienation subscale were reasonably normally distributed whereas the Affiliation and the Satisfaction with Life subscale scores were abnormally distributed with statistically significant negative skew.

$<$ Table 2 about here $>$

All correlation coefficient values among the SWBS and the subscales are shown in Table 3. The correlation coefficients between the SWBS and Affiliation, Alienation, and Satisfaction with Life subscales have statistically significant high positive correlations. There was a moderate and statistically significant positive correlation between Affiliation and Satisfaction with Life subscales but no other correlation between the subscales was statistically significant.

$<$ Table 3 about here >

Anomalous items

From the pilot study, four of the items $(5,7,12$, and 13$)$ were identified as potentially problematic. Items 7 and 13 were each left blank by three respondents. The meanings of the items were reassessed and the non-response may be related to the inadequate selection of clear words or phrases during translation and/or to unfamiliarity of the words within Arabic culture. 
Items 5 and 12, which were the subject of extended discussions during the translation process, also created statistical problems in the data. Item 5 had the highest item mean value and the least variation among all items of SWBS. This highest mean value may be related to translating this item as a general statement instead of asking about the experience of the individual. Furthermore, omitting this item from factor 2 increased the internal reliability of that factor significantly. Item 12 which asks about enjoying life was considered as a negative item from most Muslims' point view because their main purpose in the life is to gain entry to paradise in the afterlife and not just enjoying their life on Earth. Therefore, items 5, 7, 12, 13 needed to be further revised by the Expert Panel to improve their suitability for use within the Arabic Islamic culture.

The panel suggested using different words and phrases to suit the target population until they reached a consensus on the required changes to the SWBS. Items 7 and 13 in the translated Arabic version of the SWBS were revised: "a personally meaningful relationship" (Item 7) and "a personally satisfying" (Item 13). All words and phrases of Item 5 were revised to ask about the experience of the participants regarding the content of this item instead of asking them about their opinion regarding this item as a general statement. All emic words and phrases of Item 12 were modified into derived etic phrases that ask the participants about their opinion regarding enjoying life in positive terms instead of negative terms as listed in the original instrument.

Main study 
The revised Arabic version of the SWBS was pre-tested on a convenience sample of five patients. All participants in the pre-test verbalized that the words and phrases of the items were clear, not confusing, easy to understand, complete, and had significant meaning for them.

A two part questionnaire was used in the main study. The first part asked for information about demographic background, and religiosity; the second part measured the patients' spiritual well-being. Sixty-five post-CABG surgery patients at the end of their hospitalization period were invited to participate in this study and 63 agreed. These participants were receiving routine nursing care services in the cardiac medical units in large regional teaching hospitals in Jordan with ongoing cardiothoracic surgical programs in summer 2005. These hospitals represent both public and private health care sectors. These hospitals perform the vast majority of CABG surgeries for Jordanian patients and secondarily for other Arab patients from neighbouring countries. The vast majority of nurses at these institutions have the same religious affiliation as their patients. Of the participants, 74.6\% $(n=47)$ were men. The educational level of participants ranged from no formal education to postgraduate level. The employment status categories revealed that the largest group of participants $(34.9 \%, n=22)$ were retired and a quarter $(25.4 \%, n=16)$ of the participants were working full-time. Less than one-third of the participants came from another country for treatment $(30.2 \%, n=19)$.

The main study used the same procedures for data inspection, factor determination and extraction as the pilot study. The data were assessed as suitable. Examination of the scree test indicated that only two factors should be retained. These two factors explained a relatively large amount of variance (54\%). In addition, the SWBS and the subscales were correlated with respondent's religiosity which was measured by items covering both religious behavioural and religious attitudinal dimensions. Religious behavioural dimension consisted of 3 Likert scale 
format questions and asked the participants the frequency of their praying, attending the Mosque to pray, and reading from Qur'an. One item ranging from ' Unimportant' to 'Very important' was designed to measure the religious attitudinal dimension and asked the participants on the importance of their faith to them.

Table 4 presents the structure matrix of the factor loadings for each item onto each factor and shows that the majority of items loaded substantially and significantly (loading > $0.30)$ onto only one factor.

All items in factor 1 , with the exception of item 8 , related to issues concerning one's experience of a relationship with God. This factor included all the items of religious aspects of spirituality (10 items) designed by Paloutzian and Ellison (1982) to measure the religious wellbeing. All items in factor 2 were related to issues concerning existential elements of spirituality, in particular, life satisfaction, life direction and future, and life purpose. This factor included all the items of existential aspects of spirituality designed by Paloutzian and Ellison (1982) to measure the existential well-being with the exception of item 8 which loaded substantially and significantly higher on factor 1 but still also loaded on factor 2 (loading $=0.47$ ). Because item 8 loaded significantly on factor 2 and had a theoretical consistency with the existential dimension of spirituality, this item retained in factor 2 for the purposes of statistical analyses in this study. $<$ Table 4 about here >

The two-factor solution of the Arabic version of the SWBS from a sample of CABG patients showed a relatively clear factor structure. Overall, these findings are consistent with the findings of Paloutzian and Ellison (1982) that also showed a two-factor solution for SWBS. 
Table 5 presents the mean, standard deviation, range, and Cronbach's alpha of the SWBS, the two subscales, and religiosity.

$<$ Table 5 about here >

The correlations between the SWBS and its subscales are shown in Table 6. The overall SWBS had a statistically significant strong positive correlation with both subscales and there was a moderate and statistically significant positive correlation between RWB and EWB subscales. Religiosity had a statistically significant strong positive correlation with SWB and EWB and a significant moderate positive correlation with RWB. The distribution of the Arabic version of the SWBS and its subscales are presented in the Appendix.

< Table 6 about here >

The final Arabic version of the SWBS with its direct translation and the original English wording are presented in Table 7.

< Table 7 about here >

\section{Discussion}

The scores obtained from the spiritual well-being scale (SWBS) and its subscales, religious wellbeing (RWB) and existential well-being (EWB), revealed that Muslim CABG patients in this study had high average levels of SWB, RWB, and EWB with means of 103.9, 58.2, and 45.7, respectively. These findings are consistent with other studies (Bufford et al., 1991; Ellison \& Smith, 1991; Miller et al., 1998; Genia, 2001), who found that scores on the SWBS are high in various religious samples. Moreover, the mean levels of spiritual well-being (SWB), RWB, and EWB in this study are similar to other studies using patient samples. For example, the mean scores of SWB, RWB, and EWB were high in patients with breast cancer with values of 99.8, 
50.8, and 49.1, respectively (Mickley et al., 1992); were high in kidney transplant recipients with values of 102.1, 48.6, and 53.4, respectively (Martin \& Sachse, 2002); were high in adult primary care patients who seek treatment of acute and/or chronic complaints with values of 93.1, 46.7, and 46.6, respectively (Skye, 1998).

Levels of religiosity were significantly associated with levels of spiritual well-being. This finding is consistent with other studies as a growing body of research has found that religiosity or some aspects of religiosity are related positively to spirituality (Bartlett et al., 2003; Boero et al., 2005) and spiritual well-being (Mickley et al., 1992; Genia, 1996, 2001; Fehring et al., 1997; Musgrave \& McFarlane, 2004) in different populations.

Validity and reliability of the scales

The results of this study generally support the conclusions of Miller et al. (1998) who asserted that using the SWBS within different cultures shapes the responses to the scale differently. Our results showed a three-factor structure to the SWBS by using college students sample in the pilot study and a two-factor structure to the SWBS by using CABG patients sample in the main study. Findings in this study broadly support the factorial validity of the SWBS. The two-factor solution of the final version of the Arabic version of the SWBS for Jordanian and other Arab Muslim CABG patients in the main study revealed that this scale consists of two factors, representing the "religious well-being" (RWB) and "existential well-being" (EWB) subscales similar to what was originally hypothesised by the developers of the SWBS using a sample of religious university students (Paloutzian \& Ellison, 1982). Moreover, this two-factor solution was also confirmed by Kirschling and Pittman (1989) using data from 70 caregivers for 
terminally ill hospice patients, Genia (2001) using a religious university student sample, and Fernander et al. (2004) using data from 661 male prisoners with prior histories of drug use.

Although several studies, including this study, supported the two-factor solution of the SWBS, other studies suggested that this scale contains more than two factors (Ledbetter, Smith, Fischer et al., 1991, 1991; Miller et al., 1998; Scott et al., 1998). It would appear that possible reasons for this variable solution of the SWBS in several studies are using different samples and statistical techniques. Moreover, Ledbetter, Smith, Vosler-Hunter, and Fischer (1991) and Bufford et al. (1991) suggested that because the assumptions of parametric correlational techniques are not met in some studies, factor structure of the SWBS is likely to produce a variable factor solution.

This study found that there were no significant ceiling effects for the SWBS, and the data from the SWBS had a reasonable normal distribution, but had mixed results from its subscales. Concerning the overall SWBS, these findings are consistent with those of other studies using clinical samples (Bufford et al., 1991; Scott et al., 1998), but stand in contrast to those who found that the SWBS suffered from ceiling effects when used in religious samples (Bufford et al., 1991; Ellison and Smith, 1991; Ledbetter, Smith, Vosler-Hunter et al., 1991), and who suggested that this scale may suffer from ceiling effects when used in healthy or non clinical samples (Bufford et al., 1991; Scott et al., 1998).

In the main study the two-factor solution, which represents the religious and existential dimensions of spirituality, was relatively a clear and stable factor structure with a minimum level of factorial complexity. Overall, the findings of construct validity imply that spiritual well- 
being of the Muslim CABG patients in the Arabic Islamic culture consisted of horizontal (existential) and vertical (religious) aspects of spirituality.

The reliability results of the SWBS and its subscales indicated that the scales had high internal consistency. It is noteworthy that values of Cronbach's alpha for the SWBS increased from 0.66 in the pilot study to 0.83 in the main study after expert panel further revised the items that proved to be particularly problematic in the pilot study. The values of Cronbach's alpha for the SWBS and its subscales (RWB and EWB) in the main study are similar to those of other studies using the original English version of the SWBS with various samples (Ellison, 1983; Kirschling and Pittman, 1989; Bufford et al., 1991; Fernander et al., 2004), who showed that the SWBS has high reliability coefficients and internal consistency. Overall, the findings of content and construct validity and internal consistency reliability in this study indicated that the SWBS and its subscales are valid and reliable measures and can be used with the population of CABG patients in the Arabic Islamic culture.

The main limitations of this study should be noted. The sample size of the main study was relatively small which will limit the ability to generalize research findings to a large population of the hospitalized adult post-CABG surgery patients. Other limitations of the study include the ceiling effect of the RWB subscale in the main study which may result in wealer correlations between this subscale and other variables and the assessment of spiritual well-being items in the main study was based on the participants' responses to face-to-face questions at the time of the interview which may have influenced their responses. It is unknown whether or not patients gave the answers that they felt were expected by the researcher. Therefore, less honest answers might be obtained as a consequence of participants feelings might be affected 
by the presence of the researcher. Although little could be done about this, the following was intended to minimize the researcher's influence as an interviewer: a) provided participants with sufficient and adequate information and explanation about the study, their rights and confidentiality before starting collecting the data, and b) built a rapport relationship with them which gave them a feeling of comfort, safe, and confidentiality.

\section{Conclusions}

Based on a general understanding of the framework of Islam and Islamic religious influences on the vertical and horizontal dimensions of spirituality, the RWB factor focused on the vertical aspects of spirituality, which included aspects of relationships between the individual and God. Through this vertical dimension, Muslim patients become closer to God and increase their spirituality by adhering to religious practices, such as prayer, reading from the Qur'an, meditation, fasting and Zakat (the payment of fixed proportion of an individual's own money to the poor once a year). The EWB factor focused on the horizontal aspect of spirituality, which included aspects of relationships with self, others, and the environment. This factor is important for the Muslims' life, because it measures the level of their religious status during their daily life. Through this horizontal dimension, they increase their spirituality by having positive thoughts and relationships toward other people and by doing gratis activities. Examples of these gratuitous activities are caring for the weak and suffering people, encouraging and doing maaruf (good deeds), and preventing munkar (bad events or behaviors). These elements of horizontal relationship depend on the nature of the vertical relationship of the individual. In this case, the horizontal relationships with self, others, and the environment will be increased, meaningful, and worthy when the vertical relationships with God and the value system are in 
equilibrium and harmony. On the other hand, when the horizontal relationships are not right and meaningful, the individual is distant from God.

Overall, the two-factor solution of the Arabic version of the SWBS in this study appears psychometrically sound, with a higher degree of content and construct validity. This study demonstrates that the SWBS has the potential to be used outside faiths of the Judeo-Christian tradition in a meaningful way on the provision that the translation adequately reflects the practices, traditions, and culture of the intended participants. This supports the notion that the SWBS is a nonsectarian instrument that can be utilized by other religions that experience God in personal terms and by individuals from different cultures (Ellison, 1983), and stand in contrast to those who pointed out that the SWBS may be biased to the faith expressions in the Christian cultural context (Scott et al., 1998). 


\section{References}

Bartlett, S.J., Piedmont, R., Bilderback, A., Matsumoto, A.K., \& Bathon, J.M. (2003). Spirituality, well-being, and quality of life in people with Rheumatoid arthritis. Arthritis \& Rheumatism (Arthritis care \& Research), 49(6), 778-783.

Boero, M.E., Caviglia, M.L., Monteverdi, R., Braida, V., Fabello, M., \& Zorzella, L.M. (2005).

Spirituality of health workers: a descriptive study. International Journal of Nursing Studies, 42, 915-921.

Bufford, R.K., Paloutzian, R.F., \& Ellison, C.W. (1991). Norms for the Spiritual Well-Being Scale. Journal of Psychology and Theology, 19, 56-70.

Carlson, E. (2000). A case study in translation methodology using the health-promotion lifestyle profile II. Public Health Nursing, 17, 61-70.

Ellison, C. W. (1983). Spiritual well-being: Conceptualization and measurement. Journal of Psychology and Theology, 11, 330-340.

Ellison, C. W., \& Smith, J. (1991). Toward an integrative measure of health and well-being. Journal of Psychology and Theology, 19, 35-48. 
Fehring, R.J., Miller, J.F., \& Shaw, C. (1997). Spiritual well-being, religiosity, hope, depression, and other mood states in elderly people coping with cancer. Oncology Nursing Forum, 24(4), 663-671.

Fernander, A., Wilson, J.F., Staton, M., \& Leukefeld, C. (2004). An exploratory examination of the Spiritual Well-Being Scale among incarcerated black and white male drug users. International Journal of Offender Therapy and Comparative Criminology, 48(4), 403-413.

Field, A. (2004). Factor analysis using SPSS. [online] Available from http://www.sussex.ac.uk/Users/andyf/teaching/rm2/factor.pdf. [April, 2005]. 1-11.

Genia, V. (1996). I,E, Quest and Fundamentalism as predictors of psychological and spiritual well-being. Journal for the Scientific Study of Religion, 35(1), 56-64.

Genia, V. (2001). Evaluation of the Spiritual Well-being Scale in a sample of college students. International Journal for the Psychology of Religion, 11, 25-33.

Hyrkäs, K., Appelqvist-Schmidlechner, K., \& Paunonen-IImonen, M. (2003). Translating and validating the Finnish version of the Manchester Clinical Supervision Scale. Scandinavian Journal of Caring Sciences, 17, 358-364. 
Jones, E., \& Kay, M. (1992). Instrumentation in cross-cultural research. Nursing Research, 41, 186-188.

Jones, P., Lee, J., Phillips, L., Zhang, X., and Jaceldo, K. (2001). An adaptation of Brislin's translation model for cross-cultural research. Nursing Research, 50, 300-304.

Kirschling, J. M., \& Pittman, J. F. (1989). Measurement of spiritual well-being: A hospice caregiver sample. The Hospice Journal, 5, 1-11.

Ledbetter, M.F., Smith, L.A., Vosler-Hunter, W.L., \& Fischer, J.D. (1991). An evaluation of the research and clinical usefulness of the spiritual well-being scale. Journal of Psychology and Theology, 19, 49-55.

Ledbetter, M. F., Smith, L. A., Fisher, J. D., Vosler-Hunter, W. L., \& Chew, G. P. (1991). An evaluation of the construct validity of the spiritual well-being scale: A confirmatory factor analytic approach. Journal of Psychology and Theology, 19, 94-102.

Martin, J.C., \& Sachse, D.S. (2002). Spirituality characteristics of women following renal transplantation. Nephrology Nursing Journal, 29(6), 577-581.

Mickley, J.R., Soeken, K., \& Belcher, A. (1992). Spiritual well-being, religiousness and hope among women with breast cancer. Journal of Nursing Scholarship, 24(4), 267-272. 
Musgrave, C.F., \& McFarlane, E.A. (2004). Israeli oncology nurses' religiosity, spiritual wellbeing, and attitudes toward spiritual care: a path analysis. Oncology Nursing Forum, 31(2), 321327.

Miller, G., Fleming, W., \& Brown-Anderson, F. (1998). Spiritual well-being scale ethnic differences between Caucasians and African-Americans. Journal of Psychology and Theology, 26, 358-364.

Paloutzian, R. D., \& Ellison, C. W. (1982). Loneliness, spiritual well-being and the quality of life. In L. A. Peplau \& D. PerIman (eds) Loneliness: A sourcebook of current theory, research and therapy. New York: Wiley. pp. 224-237.

Scott, E. L., Agresti, A. A., \& Fitchett, G. (1998). Factor analysis of the 'spiritual well-being scale' and its clinical utility with psychiatric inpatients. Journal for the Scientific Study of Religion, 37, 314-321.

Skye, C.L. (1998). Spiritual well-being of primary care clients and their perceptions of spiritual care by primary care providers. Unpublished master's thesis, Clarkson College.

Slater, W., Hall, T. W., \& Edwards, K. J. (2001). Measuring religion and spirituality: Where are we and where are we going? Journal of Psychology and Theology, 29, 4-21. 
Table 1: Rotated Factor Structure of the Arabic SWBS on student sample in the pilot study

\begin{tabular}{|c|c|c|c|c|c|}
\hline Factor & & Items & Affiliation & Alienation & $\begin{array}{l}\text { Satisfaction } \\
\text { with Life }\end{array}$ \\
\hline \multirow{8}{*}{1} & 1 & I don't find much satisfaction in private prayer with God & .457 & & \\
\hline & 3 & I believe that God loves me and cares about me & .429 & & \\
\hline & 7 & I have a personally meaningful relationship with God & .517 & & \\
\hline & 11 & I believe that God is concerned about my problems & .578 & & \\
\hline & 12 & I don't enjoy much about life & .484 & & \\
\hline & 15 & My relationship with God helps me not to feel lonely & .605 & & \\
\hline & 17 & I feel most fulfilled when I'm in close communion with God & .574 & & \\
\hline & 19 & My relation with God contributes to my sense of well-being & .657 & & \\
\hline \multirow{7}{*}{2} & 2 & I don't know who I am, where I came from, or where I'm going & & .441 & \\
\hline & 5 & I believe that God is impersonal and not interested in my daily situations & & .407 & \\
\hline & 6 & I feel unsettled about my future & & .655 & \\
\hline & 9 & I don't get much personal strength and support from my God & & .628 & \\
\hline & 13 & I don't have a personally satisfying relationship with God & & .428 & \\
\hline & 16 & I feel that life is full of conflict and unhappiness & & .629 & \\
\hline & 18 & Life doesn't have much meaning & & .535 & \\
\hline \multirow{5}{*}{3} & 4 & I feel that life is a positive experience & & & .778 \\
\hline & 8 & I feel very fulfilled and satisfied with life & & & .421 \\
\hline & 10 & I feel a sense of well-being about the direction my life is headed in & & & .615 \\
\hline & 14 & I feel good about my future & & & .648 \\
\hline & 20 & I believe there is some real purpose for my life & & & .619 \\
\hline
\end{tabular}


Table 2: Descriptive statistics of the Arabic SWBS on student sample in the pilot study

\begin{tabular}{clcccccc}
\hline Factor & Scale & $\begin{array}{c}\text { No. of } \\
\text { items }\end{array}$ & Mean & SD & Min & Max & $\begin{array}{c}\text { Cronbach's } \\
\text { alpha }\end{array}$ \\
\hline- & SWBS & 20 & 90.3 & 9.6 & 70 & 113 & 0.66 \\
1 & Affiliation & 8 & 40.6 & 4.8 & 27 & 48 & 0.66 \\
2 & Alienation & 7 & 27.9 & 5.4 & 16 & 41 & 0.56 \\
3 & Satisfaction with Life & 5 & 21.8 & 4.5 & 6 & 30 & 0.68 \\
\hline
\end{tabular}


Table 3: Correlation between SWBS and its sub-scales on student sample in the pilot study

\begin{tabular}{lccc}
\hline & SWBS & Affiliation & Alienation \\
\hline Affiliation & $0.62^{*}$ & & \\
Alienation & $0.63^{*}$ & -0.04 & \\
Satisfaction with Life & $0.72^{*}$ & $0.29 *$ & 0.18 \\
\hline
\end{tabular}

$* p<0.01$ (2-tailed). 
Table 4: Rotated factor structure of the Arabic SWBS on CABG patient sample in the main study

\begin{tabular}{|c|c|c|c|c|}
\hline Factors & Iten & & $\begin{array}{l}\text { Religious Well- } \\
\text { Being }\end{array}$ & $\begin{array}{l}\text { Existential } \\
\text { Well-Being }\end{array}$ \\
\hline \multirow{11}{*}{1} & 1 & I don't find much satisfaction in private prayer with God & .806 & \multirow{11}{*}{.470} \\
\hline & 3 & I believe that God loves me and cares about me & .803 & \\
\hline & 5 & I believe that God is impersonal and not interested in my daily situations & .835 & \\
\hline & 7 & I have a personally meaningful relationship with God & .835 & \\
\hline & 8 & I feel very fulfilled and satisfied with life & .734 & \\
\hline & 9 & I don't get much personal strength and support from my God & .678 & \\
\hline & 11 & I believe that God is concerned about my problems & .929 & \\
\hline & 13 & I don't have a personally satisfying relationship with God & 679 & \\
\hline & 15 & My relationship with God helps me not to feel lonely & .724 & \\
\hline & 17 & I feel most fulfilled when I'm in close communion with God & .889 & \\
\hline & 19 & My relation with God contributes to my sense of well-being & .862 & \\
\hline \multirow{9}{*}{2} & 2 & I don't know who I am, where I came from, or where I'm going & \multirow{9}{*}{.565} & .550 \\
\hline & 4 & I feel that life is a positive experience & & .616 \\
\hline & 6 & I feel unsettled about my future & & .621 \\
\hline & 10 & I feel a sense of well-being about the direction my life is headed in & & .674 \\
\hline & 12 & I don't enjoy much about life & & .345 \\
\hline & 14 & I feel good about my future & & 609 \\
\hline & 16 & I feel that life is full of conflict and unhappiness & & .306 \\
\hline & 18 & Life doesn't have much meaning & & .407 \\
\hline & 20 & I believe there is some real purpose for my life & & .631 \\
\hline
\end{tabular}


Table 5: Descriptive statistics of the Arabic SWBS and religiosity on CABG patient sample in the main study

\begin{tabular}{lcccccc}
\hline Variables & $\begin{array}{c}\text { No. of } \\
\text { items }\end{array}$ & Mean & SD & Min & Max & $\begin{array}{c}\text { Cronbach's } \\
\text { alpha }\end{array}$ \\
\hline SWBS & 20 & 103.9 & 9.6 & 76 & 120 & 0.83 \\
RWB subscale & 10 & 58.2 & 4.1 & 36 & 60 & 0.90 \\
EWB subscale & 10 & 45.7 & 7.1 & 24 & 60 & 0.75 \\
Religiosity (males) & 4 & 17.6 & 3.0 & 10 & 22 & - \\
Religiosity (females) & 3 & 13.4 & 2.2 & 8 & 16 & - \\
\hline
\end{tabular}


Table 6: Correlation between the SWBS, its subscales, and religiosity on CABG patient sample in the main study

\begin{tabular}{lccc}
\hline & SWBS & Religious Well-Being & Existential Well-Being \\
\hline Religious Well-Being & $0.76^{*}$ & & \\
Existential Well-Being & $0.93^{*}$ & $0.45^{*}$ & \\
Religiosity & $0.57^{*}$ & $0.48^{*}$ & $0.50^{*}$ \\
\hline${ }^{*} p<0.01$ (2-tailed). & & &
\end{tabular}


Table 7: The Arabic version of the SWBS with its direct English translation and original wording

\begin{tabular}{|c|c|c|c|}
\hline Item & Arabic & Direct translation & Original items English \\
\hline 1 & لا أثعر بارتياح أكثر في مناجاتي وتوسلي إلى الله & $\begin{array}{l}\text { I don't find much satisfaction in prayer } \\
\text { with God. }\end{array}$ & $\begin{array}{l}\text { I don't find much satisfaction in private } \\
\text { prayer with God. }\end{array}$ \\
\hline 2 & مصيري اعلم من أنا،أو من أين أتيت،أو ما سيكون & $\begin{array}{l}\text { I don't know who I am, where I came } \\
\text { from, or where I'm going. }\end{array}$ & $\begin{array}{l}\text { I don't know who I am, where I came } \\
\text { from, or where I'm going. }\end{array}$ \\
\hline 3 & أؤمن أن الله يحبني ويحفظني برعايته & $\begin{array}{l}\text { I believe that God loves me and cares } \\
\text { about me. }\end{array}$ & $\begin{array}{l}\text { I believe that God loves me and cares } \\
\text { about me. }\end{array}$ \\
\hline 4 & أرى أن الحياة تدعو للتفاؤل & I feel that life is a positive experience. & I feel that life is a positive experience. \\
\hline 5 & اعتقد أن الله يرعى أمور حياتي اليومية. & $\begin{array}{l}\text { I believe that God is interested in my } \\
\text { daily situations. }\end{array}$ & $\begin{array}{l}\text { I believe that God is impersonal and not } \\
\text { interested in my daily situations. }\end{array}$ \\
\hline 6 & أشعر بالقلق على مستقبلي & I feel unsettled about my future. & I feel unsettled about my future. \\
\hline 7 & تربطني بالله علاقة عميقة. & I have a deep relationship with God. & $\begin{array}{l}\text { I have a personally meaningful } \\
\text { relationship with God. }\end{array}$ \\
\hline 8 & أشعر بالاكتفاء والرضا في الحياة & $\begin{array}{l}\text { I feel very fulfilled and satisfied with } \\
\text { life. }\end{array}$ & $\begin{array}{l}\text { I feel very fulfilled and satisfied with } \\
\text { life. }\end{array}$ \\
\hline 9 & وتعالىى) أستمد العون و الصبر الكافيين من الله (سبحانه & $\begin{array}{l}\text { I don't get much strength and support } \\
\text { from my God. }\end{array}$ & $\begin{array}{l}\text { I don't get much personal strength and } \\
\text { support from my God. }\end{array}$ \\
\hline 10 & أشعر بالارتياح التام بالاتجاه الذي تسير به حياتي & $\begin{array}{l}\text { I feel a sense of well-being about the } \\
\text { direction my life is headed in. }\end{array}$ & $\begin{array}{l}\text { I feel a sense of well-being about the } \\
\text { direction my life is headed in. }\end{array}$ \\
\hline 11 & اعتقل أن الله يرعاني في همومي & $\begin{array}{l}\text { I believe that God is concerned about } \\
\text { my problems. }\end{array}$ & $\begin{array}{l}\text { I believe that God is concerned about } \\
\text { my problems. }\end{array}$ \\
\hline 12 & أحب الحياة & I enjoy much about life. & I don't enjoy much about life. \\
\hline
\end{tabular}


لا تصلني بالله علاقة مرضية.

I don't have a satisfying relationship with God.

I feel good about my future.

My relationship with God helps me not to feel lonely.

I feel that life is full of conflict and unhappiness.

أرى أن الحياة مثقله بالتتاقضات والمآسي

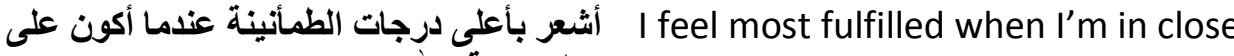

communion with God.

لا لحمل الحياة الكثير من المغنى Life doesn't have much meaning.

My relation with God contributes to my sense of well-being.

اعتقد أن هناك غاية مجديه لوجودي في الحياة
I believe there is some real purpose for my life.
I don't have a personally satisfying relationship with God.

I feel good about my future.

My relationship with God helps me not to feel lonely.

I feel that life is full of conflict and unhappiness.

I feel most fulfilled when I'm in close communion with God.

Life doesn't have much meaning.

My relation with God contributes to my sense of well-being.

I believe there is some real purpose for my life. 
Appendix: Distribution of the Arabic version of the SWBS and its subscales by demographic variables

\begin{tabular}{|c|c|c|c|c|c|}
\hline Demographic variables & Categories & $\mathrm{N}$ & SWBS & RWBS & EWBS \\
\hline Gender & $\begin{array}{l}\text { Men } \\
\text { Women }\end{array}$ & $\begin{array}{l}47 \\
16\end{array}$ & $\begin{aligned} & 104.57(9.91) \\
& 101.94(8.70) \\
\mathrm{t}= & 0.946 ; p=0.348\end{aligned}$ & $\begin{array}{c}58.15(4.32) \\
58.44(3.37) \\
\mathrm{t}=-0.243 ; p=0.809\end{array}$ & $\begin{aligned} & 46.43(7.31) \\
& 43.5(5.98) \\
\mathrm{t}= & 1.44 ; p=0.159\end{aligned}$ \\
\hline Age groups & $\begin{array}{l}<50 \text { yrs } \\
50-59 \text { yrs } \\
60-64 \text { yrs } \\
>=65 \text { yrs }\end{array}$ & $\begin{array}{l}12 \\
21 \\
15 \\
15\end{array}$ & $\begin{array}{c}101(12.11) \\
103.4(7.39) \\
104.9(10.19) \\
105.9(9.97) \\
F=0.654 ; p=0.584\end{array}$ & $\begin{array}{c}56.42(7.22) \\
58.43(3.43) \\
58.73(2.55) \\
58.87(2.39) \\
F=1.008 ; p=0.396\end{array}$ & $\begin{array}{c}44.58(7.18) \\
44.95(4.95) \\
46.2(8.55) \\
47.07(8.25) \\
\mathrm{F}=0.379 ; p=0.769\end{array}$ \\
\hline Income & $\begin{array}{l}<\text { 100JD } \\
\text { 100-199JD } \\
\text { 200-299JD } \\
>=300 J D\end{array}$ & $\begin{array}{l}10 \\
22 \\
13 \\
18\end{array}$ & $\begin{aligned} & 99.90(12.84) \\
& 100(9.65) \\
& 107.92(6.33) \\
& 108(6.92) \\
& \mathrm{F}=4.188 ; p=0.009 \\
&\end{aligned}$ & $\begin{aligned} 58.2(3.55) \\
56.68(5.98) \\
59.46(1.45) \\
59.22(1.7) \\
\mathrm{F}=1.89 ; p=0.141 \\
\end{aligned}$ & $\begin{aligned} & 41.7(9.71) \\
& 43.32(5.44) \\
& 48.46(5.61) \\
& 48.78(6.39) \\
& \mathrm{F}= 4.29 ; p=0.008 \\
&\end{aligned}$ \\
\hline Education & $\begin{array}{l}\text { None } \\
\text { Primary } \\
\text { Secondary-high } \\
\text { school } \\
\text { Post-high school }\end{array}$ & $\begin{array}{l}10 \\
14 \\
24 \\
15\end{array}$ & $\begin{array}{c}95.60(12.56) \\
104.21(4.89) \\
105.42(10.15) \\
106.73(7.42) \\
\mathrm{F}=3.49 ; p=0.021\end{array}$ & $\begin{array}{c}56(5.06) \\
59.07(1.49) \\
57.96(5.30) \\
\\
59.33(1.76) \\
\mathrm{F}=1.65 ; p=0.187 \\
\end{array}$ & $\begin{aligned} & 39.6(8.25) \\
& 45.14(4.91) \\
& 47.46(7.02) \\
& \\
& 47.4(6.21) \\
\mathrm{F}= & 3.74 ; p=0.016\end{aligned}$ \\
\hline Employment status & $\begin{array}{l}\text { Not working } \\
\text { Retired } \\
\text { Working }\end{array}$ & $\begin{array}{l}21 \\
22 \\
20\end{array}$ & $\begin{array}{c}102.1(9.09) \\
103.27(11.04) \\
106.5(8.32) \\
F=1.152 ; p=0.32 \\
\end{array}$ & $\begin{array}{c}57.9(3.81) \\
57.86(5.37) \\
58.95(2.48) \\
\mathrm{F}=0.46 ; p=0.633 \\
\end{array}$ & $\begin{array}{c}44.19(6.62) \\
42.41(7.86) \\
47.55(6.50) \\
\mathrm{F}=1.19 ; p=0.311 \\
\end{array}$ \\
\hline Participant's country & $\begin{array}{l}\text { Jordan } \\
\text { Ohter Arabic } \\
\text { country }\end{array}$ & $\begin{array}{l}44 \\
19\end{array}$ & $\begin{aligned} & 104.41(9.26) \\
& 102.74(10.58) \\
t=- & 0.630 ; p=0.531\end{aligned}$ & $\begin{array}{c}58.48(4.20) \\
57.63(3.82) \\
\mathrm{t}=-0.754 ; p=0.454\end{array}$ & $\begin{array}{c}45.93(6.82) \\
45.11(7.77) \\
\mathrm{t}=-0.423 ; p=0.673\end{array}$ \\
\hline
\end{tabular}

